\title{
Pembentukan Karakter dalam Pendidikan Makan (Studi Kasus di Raudhatul Athfal Istiqlal Jakarta)
}

\author{
Yossi Srianita ${ }^{\bowtie}$ Ma'Ruf Akbar $^{2}$, Sri Martini Meilanie ${ }^{3}$ \\ Pendidikan Anak Usia Dini Universitas Negeri Jakarta \\ DOI: $10.31004 /$ obsesi.v4i1.277
}

\begin{abstract}
Abstrak
Tujuan penelitian secara umum adalah untuk memahami secara mendalam dan mendeskripsikan pembentukan karakter dalam pendidikan makan di Lembaga PAUD Istiqlal Jakarta Pusat. Objek penelitian adalah anak yang berada pada rentang usia 4-6 tahun. Metode yang digunakan dalam penelitian ini adalah metode penelitian kualitatif studi kasus. Teknik analisis data yang digunakan dalam penelitian ini menggunakan tiga komponen model Miles dan Huberman, yaitu: 1) data condensation, 2) data display and 3) conclusion drawing/verification. Hasil penelitian menunjukan bahwa pendidikan karakter makan ditentukan tidak hanya oleh peran Guru seperti peran guru pada pembentukan karakter dalam kegiatan makan diantaranya: 1) Guru sebagai tauladan atau modelling. 2) guru sebagai pengamat atau observer, 3) guru sebagai pendukung, 4) guru sebagai fasilitator, 5) guru sebagai evaluator, tetapi peran orangtua seperti 1) memberi tauladan kepada anak-anak tentang bagaimana sikap makan yang tepat, seperti mengambil makanan sesuai kebutuhan dan bertanggungjawab menghabiskan makanan yang telah diambil. 2) memberi contoh dalam perilaku sosial saat makan dalam kelompok atau keluarga, sehingga anak-anak memperoleh pembelajaran penting tentang sikap sosial seperti: berkomunikasi efektif dengan setiap anggota keluarga.
\end{abstract}

Kata Kunci: karakter; pendidikan; cara makan.

\begin{abstract}
The purpose of the research is to understand deeply and describe the character building in the eating education at the Istiqlal Early Child Education Institution in Central Jakarta. The object of this study is the group Kindergarten A and B students ranging from 4-6 years. The method used in this study is a qualitative research of case study research. Data analysis techniques used in this study are models from Miles and Huberman, namely: 1) data condensation, 2) data display and 3) conclusion / verification. The results showed that eating character education was determined not only by the role of the teacher such as the role of the teacher in the character building in eating activities including: 1) The teacher as a role model or modeling. 2) the teacher as an observer, 3) the teacher as a supporter, 4) the teacher as a facilitator, 5) the teacher as an evaluator and the role of parents such as 1) set an example to children about how to eat properly, such as taking food according to needs and responsible for spending food that has been taken. 2) give examples of social behavior when eating in groups or families, so that children get important learning about social attitudes such as: effective communication with each family member.
\end{abstract}

Keywords: character; education; eating habits.

Copyright (c) 2019 Yossi Srianita Ma’Ruf Akbar, Sri Martini Meilanie

$\triangle$ Corresponding author:

Email Address : Yossy04srianita@gmail.com ( Depok, Jakarta )

Received 13 August 2019, Accepted 17 October 2019, Published 29 October 2019

152 | Jurnal Obsesi : Jurnal Pendidikan Anak Usia Dini, 4(1), 2020 


\section{PENDAHULUAN}

Usia dini merupakan masa kritis dalam pembentukan karakter dan pengembangan berbagai dimensi perkembangan anak. Pentingnya pembentukan karakter anak sejak dini melalui pendidikan formal, in formal dan non formal sebagai pembangunan mental bangsa. Kebijakan pemerintah disampaikan Presiden Republik Indonesia, Bapak Joko Widodo dalam Peraturan Presiden (Perpres) Nomor 87 Tahun 2017 tentang Penguatan Pendidikan Karakter. Peraturan ini, menegaskan bahwa pendidikan karakter menjadi tanggungjawab lembaga pendidikan selain pendidikan keluarga. Pentingnya lembaga Pendidikan Anak Usia Dini sebagai satuan Pendidikan jalur Pendidikan Formal, Non Formal dan Informal bertanggungjawab dan menyelenggarakan Penguatan Pendidikan Karakter (PPK). Urgensi penguatan pendidikan karakter, salah satunya adalah menghadapi kondisi degradasi moral, etika, dan budi pekerti, hingga kebijakan pemerintah yang diterapkan berkaitan dengan pentingnya penguatan pendidikan karakter bangsa.

Seharusnya pembentukan karakter dilakukan bersama dengan seluruh komponen pendidikan: orangtua, lingkungan rumah, sekolah dan masyarakat. Karakter mengandung nilai-nilai moral, terkait sikap dan perkataan. Dalam perkembangan moral sangat membutuhkan kepekaan, motivasi, perilaku dan karakter terkait sikap dan perkataan yang baik. Nuccy, dalam jurnalnya menyatakan I discuss character as a system that includes four components: moral cognition, otherrelated social emosional capacities and skills, self regarding capacities for executive control and self regulation and discourse skills for responsive engagement and an orientation for principled moral change.(Nucci, 2018) Proses pembelajaran di lembaga PAUD berlangsung sejak anak-anak hadir di sekolah sampai anak-anak kembali kepada orangtua. Dengan demikian pembentukan karakter dapat dikemas dalam berbagai aktivitas pembelajaran. Beragam cara dapat dilakukan diantaranya melalui tauladan dan pembiasaan dalam kehidupan sehari-hari. Makan merupakan sarana dalam pembentukan karakter melalui pembiasaan sehari-hari. Aktivitas makan menjadi satu wadah dalam pembentukan karakter, sebagaimana Leunga et all, menyatakan dalam jurnalnya:

In Chinese families, junior generation members are expected to show respect to the senior generation members and let them take food first. Eating might mean more than feeding in different cultures. For example, Chinese treat eating as a means of socialisation and promotion of harmony (Li, 2010). There is a need for more studies on cultural practices on mealtime practices and their impact on child development.(Leung, Lo, Tsang, \& Chan, 2017).

Dalam keluarga Cina, saat makan anak-anak diharapkan dapat menghormati yang lebih tua dengan membiarkan mengambil makanan terlebih dahulu, ini bukan hanya membangun budaya saat makan tetapi juga memperlakukan makan sebagai sarana sosial dan keharmonisan. Makna yang terdapat dalam pendangan ini bahwa pentingnya pembentukan karakter pada saat makan bersama, baik dalam keluarga atau makan bersama di sekolah. Makan bersama di sekolah, memberi pengalaman sosial, berinteraksi sesama teman dan guru dalam kelompok.

Kegiatan makan biasanya dilakukan bersama keluarga di rumah. Pada umumnya lembaga PAUD hanya menyediakan waktu untuk menikmati kudapan atau snack di pagi hari atau menu sehat tambahan berupa makanan berat setiap minggu sekali. Tetapi kondisi berbeda dengan lembaga PAUD Istiqlal. Lembaga PAUD Istiqlal, mengembangkan program fullday school, waktu belajar lebih panjang, sehingga untuk memenuhi kebutuhan fisik anak, lembaga PAUD Istiqlal tidak hanya menyediakan waktu makan kudapan atau snack time, tetapi makan siang menjadi kegiatan rutin yang penting diberikan setiap hari. Hal menarik di lembaga PAUD Istiqlal adalah tata cara makan berbeda dengan lembaga PAUD pada umumnya. Dari sisi penyajian dilakukan secara prasmanan, anak mengambil makanan sesuai porsi makan sendiri, belajar menakar sesuai kebutuhan. Kondisi ini menunjukkan bahwa di lembaga PAUD Istiqlal makan tidak hanya merupakan pemenuhan kebutuhan nutrisi untuk tumbuh kembang anak.. Tetapi waktu makan digunakan untuk penanaman 
sikap pada saat makan seperti antri mengambil makanan, menata dan merapikan alat makan dimeja.

Beberapa jurnal relevan dapat menjadi referensi dalam latar belakang penelitian. Sebagaimana jurnal yang yang menyatakan Parents completed additional items relating to control in terms of attempts to control their child's food intake and using food as a tool for controlling behavior.(Brown, 2004). Ia menunjukkan signifikan korelasi antara orang tua dan anak untuk melaporkan asupan camilan, motivasi makan. Orangtua mengontrol asupan makanan cemilan dan menggunakan makanan sebagai alat untuk mengendalikan perilaku. Jurnal berikut Mealtimes provide an opportunity for children to develop good eating behaviours, as well as learn about nutrition and food variety.(Government, 2011). Kedua jurnal ini memberikan gambaran bahwa waktu makan memberikan kesempatan bagi anak-anak untuk mengembangkan perilaku makan yang baik, serta belajar tentang nutrisi dan variasi makanan. Berdasarkan jurnal ini diketahui pembiasaan dalam sikap makan bagi anak usia dini menjadi penting terutama dalam pembentukan karakter dalam kegiatan makan. Kegiatan makan dilakukan dalam kelompok sesuai usia dan rombongan belajar, dipimpin oleh seorang guru yang berperan sebagai guru kelas dan guru makan.

Pengamatan yang dilakukan menunjukan peran guru memberikan tauladan dalam mengembangkan karakter anak di kelompok makannya, membimbing anak-anak pada kebiasaan-kebiasaan baik, larangan-larangan untuk sikap yang tidak baik, bujukan dan batasan yang jelas tentang sebuah nilai, seperti: komunikatif, memiliki rasa tanggungjawab, disiplin, dan memiliki sikap syukur.

Sedangkan keterlibatan orangtua dalam mendukung kegiatan makan bahwa di rumah diberikan pengalaman makan yang positif, mengembangkan sikap-sikap yang baik saat makan. Dikatakan van der Horst pada jurnalnya: This study showed that a relatively new parenting style of overprotection is relevant for children's eating behaviors. Overprotective parents reported food parenting practices that are known to be beneficial for children's food intake, such as modelling healthy food intake, as well as more unfavorable practices such as pressure.(van der Horst \& Sleddens, 2017). Orangtua yang over protektif dalam memberikan pengalaman makan dalam hal ini tidak menguntungkan karena anak-anak berada di bawah tekanan. Dapat dijelaskan keterlibatan orangtua adalah memberikan pengalaman makan yang positif kepada anak. Sehingga pengalaman makan yang baik, karakter saat makan baik sikap dan perkataan yang baik dibawa anak-anak pada saat makan di sekolah. Dengan demikian pendidikan makan merupakan upaya pembentukan karakter yang didukung kedua peran guru dan orangtua.

Pembentukan karakter ditunjukkan dengan perilaku saat makan yang tertanam dalam pribadi anak usia dini di Lembaga PAUD Istiqlal. Gambaran karakter tersebut menjadi keunikan dan pembeda peserta didik Raudhatul Athfal Istiqlal Jakarta dengan peserta didik di lembaga pendidikan lain. Diantara karakter yang dikembangkan terdapat empat karakter yang ditunjukkan cukup kuat dalam kegiatan makan diantaranya: mandiri, disiplin, tanggung jawab, dan komunikatif. Sikap ini ditunjukkan pada kegiatan awal sebelum makan saat makan dan setelah makan.

Definisi tentang karakter ini menunjukkan kecenderungan dalam perilaku, yang berakar pada kepribadian, mengintegrasikan perilaku, sikap dan nilai-nilai. John Dewey (1922) dalam Althof \& Berkowitz mendefinisikan karakter sebagai habit dan efek konsekuensi dari tindakan terhadap kebiasaan tersebut. Orientasi perilaku memiliki warisan penting untuk pengembangan di lapangan. (Althof \& Berkowitz*, 2006). Secara sederhana dapat diartikan pengertian karakter adalah tabiat atau kebiasaan untuk melakukan hal yang baik. Untuk melengkapi pemahaman tentang karakter, maka perlu mengenali dan memahami pengertian karakter.(Thomas Lickona, 2012). Dari dua pendapat ini, diperoleh pengertian karakter adalah penggabungan tiga komponen pengetahuan moral, perasaan terkait reaksi emosional dan nilai-nilai yang dibangun di dalam diri yang kemudian mengarahkan tindakan dalam kehidupan sosial yang bermoral. 
Pendapat lain saling terkaitnya karakter dengan moral. Badhwar, menyatakan a moral character is the set traits, good or bad, that that make someone the kind of person she is.(Badhwar, 2017). Karakter moral adalah sperangkat sifat, baik dan buruk yang membuta seseorang menjadi seperti dia atau tanda yang khas.

Definisi karakter yang dapat disimpulkan berdasarkan beberapa pendapat di atas, karakter adalah sitem internalisasi moral knowledge, moral feeling dan moral action di dalam diri melalui proses pengetahuan moral yang mendorong dan menggerakkan sikap perilaku untuk merespon secara emosional terkait nilai-nilai kehidupan yang dapat diterima secara sosial yang kemudian membetuk kepribadian.

Dasar pemikiran yang berkaitan dengan pembentukan karakter menggunakan Teori perkembangan moral Kohlberg, Ralph Linton, Vygotsky, Ki Hajar Dewantara, dan Jean Peaget. Konsep pendidikan karakter mengacu pada teori Kholberg, bahwa tahapan perkembangan moral agama menurut Kohlberg, bahwa anak-anak mulai berada pada tahap Moralitas Pascakonvensional, mulai mengerti dan membuat aturan, memberi pilihan dan memutuskan bersama berdasarkan prinsip diri sendiri, mulai membuat aturan sesuai dengan standar sosial yang dapat diterima secara sosial. Pendapat lain yang sesuai adalah pernyataan Santrock tentang perkembangan moral, Moral Development involves changes in thoughts, feelings and behaviors regarding standarts of right and wrong.(Santrock, 2007). Bahwa anak mulai mengerti standar perilaku benar dan salah.

Berdasarkan pandangan Linton, Vygotsky, Jean Peaget, Ki Hajar Dewantara, dan Kohlberg, menunjukkan terbentuknya pribadi seseorang dalam masyarakatnya, penekanan utama dalam pendidikan karakter adalah pentingnya pendidikan keluarga sebagai titik tolak, dan lembaga pendidikan sebagai pelengkap dari terbentuknya karakter seseorang.

\section{METODOLOGI}

Penelitian kualitatif ini menggunakan pendekatan studi kasus. Penilitian yang disusun secara kompleks, menyeluruh dan rinci dapat dilakukan dengan pendekatan studi kasus. Robert K Yin (n.d), menyatakan studi kasus adalah strategi pilihan penelitian yang mengungkapkan tentang bagaimana atau mengapa dan peneliti memiliki kontrol atas kejadian tersebut. Fokus penelitian studi kasus adalah pada fenomena kontemporer dalam konteks kehidupan nyata.(Robert K Yin., n.d.) Menurut Sagadin (1991) Starman, menyatakan studi kasus adalah sebuah studi digunakan saat kita menganalisa dan menggambarkan, misalnya setiap orang secara individu, aktivitasnya, kebutuhan khusus, situasi kehidupan, riwayat hidup, dan lain-lain.(Starman, 2013). Berdasarkan pendapat tersebut, dapat diambil kesimpulan, pendekatan studi kasus merupakan bagian dari metodologi penelitian kualitatif, yang menekankan pada prespektif peneliti yaitu pandangan subyektif peneliti pada situasi tertentu, menganalisa dan menggambarkan tentang subjek penelitian.

Pelaksanaan penelitian ini dilakukan di lembaga PAUD Istiqlal, pada semester I tahun ajaran 2018/2019, yaitu pada bulan Maret sampai dengan Mei 2019 yang berada di gedung Masjid Istiqlal Lantai dasar, Jln. Taman Wijaya Kusuma, Jakarta Pusat. Penelitian kualitatif ini menggunakan pendekatan studi kasus.

Pemilihan tempat penelitian ini didasarkan pada alasan yang dinyatakan Spredley mengemukakan saran yang dapat dipertimbangkan dalam pemilihan latar penelitian: 1) sederhana hanya satu situasi tunggal, 2) mudah dilakukan, 3) tidak kentara dalam melakukan penelitian, 4) mudah memperoleh izin, dan 5) kegiatan terjadi secara berulangulang.(James P. Spradley, 1997). Dalam hal ini lembaga PAUD Istiqlal dipilih sebagai tempat penelitian memenuhi empat kriteria tersebut.

Data dan sumber data yang menjelaskan dan memberikan informasi atau data yang dikumpulkan sehubungan dengan fokus dan sub fokus penelitian. 
Untuk mendapat data dibutuhkan sumber data. Sumber data dalam penelitian adalah darimana data dapat diperoleh.(Arikunto, 2013). Menurut Moleong (1998) dalam Arikunto, Sumber data penelitian kualitatif adalah tampilan berupa kata-kata lisan atau tertulis yang dicermati oleh peneliti dan benda-benda yang diamati sampai detailnya agar dapat ditangkap makna yang tersirat dalam dokumen atau bendanya.(Arikunto, 2013).

Penelitian kualitatif menggunakan informan sebagai sumber data. Peneliti dan informan harus saling bekerjasama dan memahami permasalahan dan memahami tentang variable yang diteliti. untuk mempermudah mengidentifikasi sumber data, terdapat klasifikasi 3 informan dengan singkatan huruf $\mathrm{p}$ dari bahasa Inggris, yaitu: $\mathrm{p}$ (person); sumber data berupa orang, $\mathrm{p}$ (place); sumber data berupa tempat, $\mathrm{p}$ (paper); sumber data berupa symbol.(Arikunto, 2013). Menurut Suparlan dalam Hamid Patilima, informan adalah pemberi informasi.(Patilima Hamid, 2007).

Dapat dijelaskan bahwa informan dalam penelitian adalah sumber atau orang yang benar-benar memahami permasalahan dan memberikan informasi terkait penelitian. Terkait sumber data dalam penelitian ini, infroman penelitian adalah kepala sekolah, guru, orangtua dan anak. Didasari kebutuhan akan informasi terkait dengan pembentukan karakter dalam pendidikan makan, karena sumber data merupakan informan kunci dalam kegiatan makan di lembaga PAUD Istiqlal, maka informan sebagai sumber data dalam penelitian adalah kepala sekolah, guru, anak dan orangtua murid. Karena informan terlibat secara langsung dalam penelitian. Pandangan ini mengacu kepada kriteria informan Spradley, mendefinisikan informan adalah seorang pembicara asli (native speaker) yang berbicara dengan mengulang kata-kata, frase dan kalimat dalam bahasa atau dialeknya sebagai model imitasi dan sumber informasi.(James P. Spradley, 1997).

Prosedur Pengumpulan Data Dan Perekaman Data berdasarkan pengumpulan data menurut Moleong (1998) dalam Pattilima, dikatakan bahwa peneliti melekat erat dengan subjek penelitian. Itulah sebabnya dalam pengambilan data dituntut adanya pengamatan mendalam (in-depth observation) dan wawancara mendalam (in-depth interview).(Patilima Hamid, 2007). Penelitian kasus menggunakan teknik pengumpulan data yang lazim digunakan dalam penelitian kualitatif. Teknik pengumpulan data dalam penelitian kasus adalah pengamatan (observasi), wawancara dan dokumentasi.

Analisis data secara induktif (inductive) menjelaskan bahwa dalam penelitian kualitataif dilakukan dengan mendahulukan penalaran secara induktif dimana data diperoleh saat berada dilapangan. dan hasil penelitian dirundingkan dan disepakati bersama.(Arikunto, 2013). Oleh karena itu, peneliti harus ikut terlibat secara langsung dalam proses pengumpulan data sehingga data tersebut dapat dipertanggungjawabkan sebagai hasil dari penelitian. Miles and Huberman, menyatakan tentang definisi analisis data We define analysis as consisting of three concurent flows of activity: data reduction, data display and conclusion drawing / verification.(Matthew B. Miles., 1994). Bahwa terdapat tiga komponen dalam analiss data studi kasus, terdiri dari tiga arus kegiatan yang bersamaan: reduksi data, tampilan data, dan penarikan kesimpulan / verifikasi.

\section{HASIL DAN PEMBAHASAN}

Pembentukan karakter dalam Pendidikan makan di Raudhatul Athafal Istiqlal merupakan kesatuan yang utuh dalam pendidikan anak usia dini. Berdasarkan triangulasi data diperoleh gambaran tentang kondisi kegiatan makan siang, menjadi rangkaian satu kesatuan dalam kegiatan rutin harian dalam Kegiatan Belajar Mengajar (KBM). Raudhatul Athfal Istiqlal, menyiapkan kegiatan makan siang untuk anak-anak dengan tujuan agar anak-anak terbiasa berperilaku yang baik dan benar selama kegiatan makan siang dan perilaku ini dapat membentuk karakter anak. Langkah-langkah atau tahapan yang dilakukan dalam proses makan siang di Raudhatul Athfal Istiqlal, 1) Persiapan, 2) Pelaksanaan Makan 3) Penutupan. 
Langkah pertama, adalah persiapan, Lembaga PAUD Istiqlal menyiapkan perencanaan menu untuk memenuhi kebutuhan gizi seimbang dalam pertumbuhan dan perkembangan anak usia dini. Daftar menu makanan disusun bersama tim yaitu kepala sekolah dan guru yang kemudian disepakati dan disetujui bersama. Menu makanan terdiri dari nasi sebagai makanan pokok, sayur, buah, lauk sebagai sumber protein dan vitamin, air mineral ditambahkan dengan menu pelengkap seperti kerupuk. Setiap hari menu makanan berganti sesuai dengan daftar menu yang telah ditetapkan. Persiapan kedua, penataan dan pendistribusian makanan di unit pendidikan terkait. Di Raudhatul Athfal Istiqlal khususnya penataan makanan di tempatkan pada wadah-wadah makanan yang layak seperti termos tempat penyimpanan nasi, mangkok sayur, piring buah, teko berisi air mineral, sendok nasi, sendok sayur, toples berisi kerupuk, tudung saji sebagai penutup makanan. Makan sebagai satu mediator dalam pendidikan sebagai upaya pembentukan karakter. Sesuai yang dikatakan oleh Brom and other, Healty eating, what children eat effects their skeletal growth, body shape and susceptibility to disease.(Santrock, 2007). Makan sehat adalah apa yang dimakan anak-anak mempengaruhi pertumbuhan mereka, bentuk tubuh dan kerentanan terhadap penyakit. Makan harus dilakukan untuk memenuhi kebutuhan fisik, dalam rangka melancarkan pertumbuhan dan perkembangan anak.

Prosedur kegiatan sebelum makan dilakukan secara berurutan dan teratur: 1) berbaris antri masuk kamar mandi 2) berdo'a sebelum masuk kamar mandi, 3) mencuci kedua telapak tangan dengan sabun tangan, 4) kembali ke dalam barisan 5) berdo'a keluar kamar mandi, 6) berjalan antri menuju kelompok makan, 7) duduk dengan tenang di kelompok makan. Setelah tiba di kelompok makan, anak-anak duduk pada tempat yang disediakan dan guru duduk pada posisi tengah dimana menjangkau pandangan pada semua anak dan memastikan posisi guru dapat menjangkau anak-anak yang membutuhkan dukungan saat makan.

Prosedur saat makan dilakukan secara runut dan teratur, yaitu: 1) Berdo'a sebelum makan, 2) Guru menginformasikan tentang menu makanan yang telah disajikan, terdapat nasi, lauk, sayur, buah, kerupuk, dan air. Menu makanan diperkenalkan pada anak-anak, informasi tentang kandungan gizi yang terdapat dalam makanan menjadi topik di meja makan, satu persatu dan anak-anak tampak mendengarkan dengan fokus dan sabar menunggu giliran. 3) guru mempersilahkan anak-anak antri mengambil alat makan, yaitu piring, gelas, sendok dan garpu. 4) mempersilahkan anak-anak menata alat makan di hadapan mereka, 5) memberi kesempatan bergiliran mengisi air pada gelas setiap anak, 6) guru membuka piring dan mengambil buah dengan jumlah tertentu dan meletakkannya di atas piring, 7) secara bergiliran anak-anak mengambil buah dan meletakkan di piring, setelah semua anak selesai, semua mulai makan buah yang telah diambil, 8) guru memulai mengambil makanan diawali dengan mengambil nasi sesuai kebutuhan atau porsi makan, kemudian diikuti secara bergiliran oleh anak-anak.

Peran Guru dalam pembentukan karakter dalam pendidikan makan. Guru memiliki peran penting dalam pendidikan, berbagai aktivitas pembelajaran di lembaga pendidikan dapat berjalan dengan keberadaan dan peran guru. Peran guru pada pembentukan karakter dalam kegiatan makan diantaranya: 1) Guru sebagai tauladan atau modelling. 2) guru sebagai pengamat atau observer, 3) guru sebagai pendukung, 4) guru sebagai fasilitator, 5) guru sebagai evaluator. Peran guru sebagai modelling memberikan contoh cara makan yang baik dengan mengawali untuk mengambil menu tersebut. Tauladan atau modelling guru dalam kelompok makan, menekankan pada tujuan membentuk karakter melalui pendidikan makan. Anak-anak dalam kelompok makan dapat belajar tentang adab saat makan, mengamati perilaku makan yang baik, cara berbicara yang baik saat makan, mau mencoba menu makanan, walaupun anak belum mengetahui rasa makanan tersebut, belajar mensyukuri makanan yang Allah berikan dan anak melakukan seperti yang dicontohkan guru. Pendidikan makan dibimbing oleh seorang guru, maka guru berperan penting dalam pembentukan karakter dalam pendidikan makan sebagaimana dikatakan Hughes, use 
example from his life as a educator to try to address what is the good teachers.(Marsh., 2008). Guru harus memberikan contoh dari hidupnya sebagai pendidik yang baik. Dalam berbagai aktivitas pembelajaran di lembaga, guru memiliki peran yang sangat penting. The result provide some support for both the modelling and control theories of parental inuence.(Brown, 2004). Peran kedua, guru sebagai pengamat atau observer. Saat kegiatan makan telah dimulai, guru telah menjadi tauladan dalam berbagai sikap dan perilkau saat makan, guru berperan sebagai pengamat. Guru mengamati setiap aktivitas anak saat makan, meliputi aktivitas; duduk, sikap berdo'a, menata alat makan, mengisi air ke dalam gelas, mengambil makanan sesuai prekiraan kebutuhan anak, menggunakan sendok dan garpu, bertanggungjawab mengahabiskan makanan yang telah diambil, mendengarkan Bahasa dan ungkapan anak saat diskusi dan berbagai aktivitas lainnya yang penting diamati guru agar guru dapat mengukur ketercapaian atau progress perkembangan anak dalam kegiatan makan

Berbagai sumber dalam pendidikan sepakat bahwa orangtua adalah madrasah utama, dimana tempat pertama kali pendidikan itu di mulai yaitu ayah dan ibu dalam keluarga serta lingkungan di sekitar keluarga. Orangtua menjadi pelaku makan yang baik melalui cara makan dan sikap serta reaksi terhadap makanan pada saat makan. Keterlibatan orangtua dalam pendidikan makan, termasuk memberi pengalaman makan yang baik bersama keluarga, sebagaimana jurnal yang dikemukan, Recent studies have identified the protective function of shared family meals, including the dimensions of successful family mealtimes (e.g., frequency, joint interaction, information sharing, deliberateness, and parenting style.(Kiser, Medoff, Black, Nurse, \& Fiese, 2010). Studi terbaru telah mengidentifikasi fungsi makan bersama keluarga, termasuk dimensi waktu makan bersama keluarga yang sukses dalam frekuensi, interaksi bersama, berbagi informasi, kesengajaan, dan gaya pengasuhan. Artinya keluarga atau orangtua terlibat dalam makan bersama anak dirumah akan membantu suksesnya perilaku baik anak.

Di lembaga PAUD Istiqlal keterlibatan orangtua pada bagian keteladanan atau modelling adalah 1) memberi tauladan kepada anak-anak tentang bagaimana sikap makan yang tepat, seperti mengambil makanan sesuai kebutuhan dan bertanggungjawab menghabiskan makanan yang telah diambil. 2) memberi contoh dalam perilaku sosial saat makan dalam kelompok atau keluarga, sehingga anak-anak memperoleh pembelajaran penting tentang sikap sosial seperti: berkomunikasi efektif dengan setiap anggota keluarga. Sikap sosial yang dibiasakan di rumah tentu akan menjadi sikap yang ditampilkan anakanak di sekolah. Kondisi ini sesuai dengan pandangan Contento et al.,(1993) found a relationship between mothers' health motivation and the quality of children's diets. Research also indicates that children may not only model their parents' food intake, but also their attitudes to food and their body dissatisfaction.(Government, 2011) Anak-anak tidak hanya melihat model asupan makan makan orangtua mereka, tetapi juga melihat sikap orangtua terhadap makanan dan ketidakpuasan terhadap makanan.

Untuk mendorong keberhasilan atau kegagalan pendidikan dapat dilakukan asesmen. Termasuk dalam pengembangan karakter, melihat sejauh mana keberhasilan dalam menerapkan nilai-nilai karakter. Bredekamp \& Rosegrant dalam Puckett \& Deborah menyatakan: Assessment is an integral part of teaching.(Diffily, 2004). Terdapat beberapa nilai karakter yang saling berkaitan membentuk nilai karakter dalam pendidikan makan yaitu: kemandirian, dsiplin, tanggungjawab dab komunikatif.

Karakter pertama, membentuk dan membiasakan karakter mandiri yang diperoleh dalam kelompok makan, dengan memberi kesempatan dan pengalaman pada setiap kegiatan makan, anak-anak mengambil peralatan makan dan melibatkan anak-anak menata alat makan mereka di atas meja dihadapan mereka, sebagai penentu area makan mereka.

Karakter kedua disiplin, Sikap anak saat mengarahkan dirinya pada perilaku yang benar saat makan, seperti mengikuti aturan yang telah disepakati saat makan, anak mampu mengatur diri sendiri atau mengenal aturan saat makan, mengatur diri saat duduk di meja makan, menagtur diri bicara saat makan dalam kondisi mulut kosong, mengatur diri untuk 
menata dan menyimpan alat makan, mengatur diri untuk menyelesaikan waktu makan dan menggunakan sendok dan garpu agar tidak menimbulkan bunyi pada saat makan.

Karakter ketiga, tanggungjawab, guru membangun karakter ini dalam proses sebelum makan, saat makan dan sesudah makan. menata perlengakapan makan, meletakkan kembali perlengkapan makan yang telah digunakan, bertanggungjawab dengan makanan yang diambil dan menghabiskan makanan yang sudah diambil, dan meletakkan alat makan kembali ke tempatnya setelah selesai makan.

Karakter keempat komunikatif, Sikap komunikatif dibangun dalam diskusi, bertukar informasi tentang pengetahuan yang terkandung gdalam menu makanan, berinteraksi dengan guru dan teman-teman dikelompoknya. Mendiskusikan nilai-nilai yang positif saat makan, seperti meminta izin bila membutuhkan sesuatu yang ada dimeja makan. Berdasarkan uraian tentang nilai-nilai karakter, Berkowitz \& Grych, (1998) menyampaikan Four foundation components of character (social orientation, Self control, compliance, self esteem anda four moral component of character (empathy, conscience,moral reasoning, altruism) we reidentified.(Marvin W. Berkowitz, 2000)

Berdasarkan pandapat ini terdapat delapan daftar karakteristik yang menandai perkembangan moral anak usia dini. Tiga karakteristik awal pengembangan moral, anak fokus pada pengembangan diri, yaitu:1) kesadaran diri 2) pengendalian diri, 3) harga diri, 4) penalaran moral. Pada pengembangan karakter berikutnya, mulai pemahaman anak terhadap peraturan sosial dan budaya konsekuensi tindakannya terhadap perasaan atau kebutuhan orang lain, yaitu: 1) memikirkan orang lain dan membangun hubungan sosial, 2) memiliki perilaku prosocial behavior (berorientasi sosial), 3) empati memikirkan orang 4) membangun hubungan sosial.

Faktor penghambat pembentukan karakter dalam kegiatan makan, terdapatnya reaksi negative dalam waktu makan. Dikatakan Smith, 1) avoid negative reactions to picky eaters. Hindari reaksi negative terhadap pemilihan makanan. 2) Physically forcing a child to eat or using food for disciplinary purpose does not remove a child's dislike for a food.(Smith, Theodore, n.d.) (Smith, Theodore, n.d.) memaksa anak secara fisik untuk makan atau menggunakan makanan untuk tujuan disiplin, tetapi tidak menghilangkan ketidaksukaan anak terhadap suatu jenis makanan. 3) Parenting style of overprotection. Anak-anak berada dibawah tekanan orang dewasa menyebabkan anak-anak kesulitan mengembangkan potensi yang terdapat dalam dirinya seperti, mneyampaikan harapan dan keinginan, mengambil keputusan karena tidak mendapatkan kesempatan atau pengalaman terkait karakter ingin dibentuk dalam diri anak.

Dengan demikian telah diperoleh gambaran secara mendalam tentang pembentukan karakter dalam pendidikan makan, terkait Pendidikan Makan, Peran Guru Dalam Pendidikan Makan, Keterlibatan Orangtua Dalam Pendidikan Makan, Karakter Yang Terbentuk Dalam Pendidikan Makan, Faktor Pendukung Dan Penghambat Karakter Dalam Pendidikan Makan.

\section{SIMPULAN}

Pendidikan makan merupakan rangkaian pembelajaran yang dilakukan dalam sebauh proses makan bersama dalam kelompok sebagai upaya pembentukan karakter anak sejak dini dan pemenuhan membutuhkan asupan gizi seimbang, melalui menu makanan sehat dibutuhkan oleh tubuh untuk menunjang pertumbuhan fisik dan perkembangan anak. Pendidikan karakter makan ditentukan oleh peran Guru, keterlibatan orangtua dan faktor pendukung. Peran guru pada pembentukan karakter dalam kegiatan makan diantaranya: 1) tauladan atau modelling. 2) pengamat atau observer, 3) guru sebagai pendukung, 4) guru sebagai fasilitator, 5) guru sebagai evaluator. Keterlibatan orangtua dalam pembentukan karakter 1) keteladanan atau modelling, 2) Fasilitator atau menyediakan sesuai kebutuhan makan anak. 3) mendukung pola makan di sekolah dan rumah memiliki pola makan yang sama. Faktor pendukung: 1) Sikap dan kebiasaan makan anak pada tahun-tahun pertama 
kehidupannya sangat mendukung sikap pada saat makan berikutnya sehingga mendukung pembentukan karakter. 2) suasana makan yang menyenangkan dan 2) komitment memberikan pengalaman penting saat makan. 4) bersikap tenang dan menunggu jika anakanak kehilangan minat pada makan dan membuang waktu di meja makan. Kedua peran tersebut akan dapat membentuk karakter yang sangat baik untuk anak - anak dan proses tersebut akan tertanam dalam jangka panjang: mandiri, disiplin, tanggungjawab, dan komunikatif.

\section{UCAPAN TERIMAKASIH}

Dengan terlaksananya penelitian sampai tersusunnya artikel ini, kami mengucapkan terima kasih banyak, terutama kepada dosen pembimbing, pihak sekolah tempat penelitian dan team pengelola Jurnal Obsesi dan Reviwer, sehingga artikel ini dapat terbit.

\section{DAFTAR PUSTAKA}

Althof, W., \& Berkowitz*, M. W. (2006). Moral education and character education: their relationship and roles in citizenship education. Journal of Moral Education, 35(4), 495518. https:// doi.org/10.1080/03057240601012204

Arikunto, S. (2013). Prosedur Penelitian, Suatu Pendekatan Praktik, (Jakarta: Rineka Cipta, 2013).,h.23. 23.

Badhwar, N. K. (2017). Moral Character. In International Encyclopedia of Ethics (pp. 1-13). https:/ / doi.org/10.1002/9781444367072.wbiee354.pub2

Brown, R. (2004). Children's eating attitudes and behaviour: a study of the modelling and control theories of parental influence. Health Education Research, 19(3), 261-271. https:// doi.org/10.1093/her/cyg040

Diffily, M. B. P. \& D. (2004). Margeret B. Puckett \& Deborah Diffily, Teaching Young Children, An Introducing to The Early Childhood Profession. (Delmar Learning, Thamson: 2004).,h.131. 131.

Government, A. (2011). Making mealtimes positive, relaxed and social., Getup \& Graw: healthyeating and physicalactivity for early childhood- familybook ( internet/publications/publishing.

James P. Spradley. (1997). Democratic temperament: the legacy of William James. Choice Reviews Online, 35(04), 35-2390-35-2390. https:/ / doi.org/10.5860/CHOICE.35-2390

Kiser, L. J., Medoff, D., Black, M. M., Nurse, W., \& Fiese, B. H. (2010). Family Mealtime QSort: A measure of mealtime practices. Journal of Family Psychology, 24(1), 92-96. https:// doi.org/10.1037/a0017946

Leung, C., Lo, S. K., Tsang, S., \& Chan, R. (2017). Child learning and family mealtime environment, parenting style and family functioning among preschoolers in Hong Kong. Asia Pacific Journal of Social Work and Development, 27(2), 69-82. https:/ / doi.org/10.1080/02185385.2017.1335228

Marsh., C. (2008). Becoming A Teacher, Knowledge, Skill and Issues., Perason. 2.

Marvin W. Berkowitz, J. H. G. (2000). Early Character Development and Education. (University of Missouri-St. Louis). 57.

Matthew B. Miles., A. M. H. (1994). (1994). Qualitative Data Analysis, An Expanded Sourcebook Second Edition, Thousand Oaks, London New Delhi: Sage Publication., h.24-25.

Nucci, L. (2018). Character: A Developmental System., Handbook of Moral. University of California, Berkeley. Correspondence concerning this article should be addressed to Larry Nucci, Graduate School of Education, University of California, 2121 Berkeley Way MC 1670, Berkel.

Patilima Hamid. (2007). Metode Penelitian Kualitatif, (Bandung: Alfbeta).

Robert K Yin. (n.d.). Case Study Research Design And Methods, Second Edition. (London, Sage Publications)., h.1-2.

Santrock, J. W. (2007). Child Development, Eleven edition, McGraw Hill International Edition: 2007. 
DOI: 10.31004/obsesi.v4i1.277

Smith, Theodore, E. (n.d.). Making Mealtime a guide for Preschoolers A Guide for Techers (California State Department of Education: h.5. 5.

Starman, A. B. (2013). The case study as a type of qualitative research, Master of library science, Bergantova 13, SI-1215 Medvode, Slovenia; e-mail for correspondence: biba.starman@ff.uni-lj.si Journal Of Contemporary Educational Studies 1/2018 28. Journal Of Contemporary Educational Studies, 28-43.

Thomas Lickona. (2012). Educating For Character, Mendidik untuk Membentuk Karakter, (Bandung, Bumi Aksara). 81.

van der Horst, K., \& Sleddens, E. F. C. (2017). Parenting styles, feeding styles and foodrelated parenting practices in relation to toddlers' eating styles: A cluster-analytic approach. PLOS ONE, 12(5), e0178149. https:/ / doi.org/10.1371/journal.pone.0178149 